\title{
In Situ Biofilm Formation on Titanium, Gold Alloy and Zirconia Abutment Materials
}

Fadi Ismail*, Michael Eisenburger, Sebastian Grade and Meike Stiesch

Clinic of Prosthetic Dentistry and Biomedical Materials Science, Hannover Medical School, Hannover, Germany

*Corresponding author: Fadi Ismail, Clinic of Prosthetic Dentistry and Biomedical Materials Science, Hannover Medical School, Hannover, Germany, Tel: +0049 511 532 4778; Fax: 0049511532 4790; E-mail: Ismail.Fadi@mh-hannover.de

Received date: Oct 28, 2016; Accepted date: Nov 15, 2016; Published date: Nov 22, 2016

Copyright: (C) 2016 Ismail F et al. This is an open-access article distributed under the terms of the Creative Commons Attribution License, which permits unrestricted use, distribution, and reproduction in any medium, provided the original author and source are credited.

\begin{abstract}
Background: Biofilm formation on trans-gingival implant surfaces is a common reason for local inflammation of the peri-implantary tissue and can lead to implant loss. The aim of the current in situ study was to evaluate biofilm formation on titanium, gold alloy and zirconia abutment materials directly in the trans-gingival region.

Materials and Methods: Specimens were attached to implant healing abutments and were inserted in 8 patients for 14 days. Confocal laser scanning microscopy was used to measure biofilm height and surface coverage.

Results: Titanium showed a mean biofilm height of $10.8 \mu \mathrm{m}$ and a surface coverage of $26.5 \%$. For gold alloy, a height of $14.6 \mu \mathrm{m}$ and coverage of $27.3 \%$ was found. Zirconia had a biofilm height of $2.7 \mu \mathrm{m}$ and coverage of $10.5 \%$. No statistically significant difference between the three materials was found. However, zirconia tended to form less biofilm than the other materials.

Conclusion: All three materials seem to be suitable for the use as abutment material. Zirconia appeared to have the most favourable biological and aesthetic properties.
\end{abstract}

Keywords: Biofilm adhesion; Dental implants; Confocal laser scanning microscopy; Titanium; Gold alloys; Zirconia

Abbreviations: AFM: Atomic Force Microscopy; CLSM: Confocal Laser Scanning Microscopy; $\mathrm{R}_{\mathrm{a}}$ : Roughness Average

\section{Introduction}

During the past 10 years, implants have become an important option to replace missing teeth. The long-term success of dental implants depends on various factors, such as suitable distribution of stress during occlusal loading to the implant supporting bone, appropriate prosthetic denture design and the structure of the implant surface [1-3].

Furthermore, biological factors such as biofilm formation and the risk of subsequent inflammation of the peri-implant tissue can adversely influence the success of implant treatment [4]. The formation of bacterial biofilm on the implant surface is not only a major factor for early implant loss during osseointegration but also for late implant failure after prosthetic reconstruction [5]. Many investigations have shown that a healthy peri-implant mucosa plays an important role in the survival and success of implants [6].

Titanium and gold alloy have been frequently used for several years for implant abutments or prosthetic superstructures because of their superior mechanical properties. Due to the increasing demand for aesthetic reconstructions, zirconia abutments have been launched on the dental market. Because of their high mechanical stability, Yttrium stabilised zirconia abutments can be used in the anterior and posterior regions to support all-ceramic restorations [7].
A variety of studies have shown that implant material and implant roughness in the peri-implantary region significantly influence biofilm formation. With two-part implant systems, different materials can be used for the implant abutment and for the implant. The ideal abutment material should hinder the adherence of periopathogens in its transmucosal area and at the same time support adherence of epithelial mucosa cells.

Several in vivo and vitro studies have been carried out on the adhesion of biofilms to various dental materials, such as ceramics, gold, amalgam and composite [8,9]. Hahn et al. found less plaque formation in vivo on ceramic surfaces after no oral hygiene (3 days) than on natural tooth surfaces [10]. These measurements were performed on samples attached to the cervical region of natural teeth. In situ, only a thin biofilm layer was found on ceramic $(1-6 \mu \mathrm{m})$ in comparison to gold or amalgam $(11-17 \mu \mathrm{m})$, when samples were fixed on an acrylic splint in the upper jaw [8]. However, there have been no published comparisons of biofilm formation on the three important abutment materials, gold alloy, titanium and zirconia, with samples in the peri-implantary region.

For the investigation of the biofilm formation it is difficult to collect biofilm grown in situ, as the film is fragile and can easily be damaged during harvesting. On the other hand, it is unacceptable to use chemical and radioactive markers in the oral cavity to investigate the biofilm. Therefore, in situ models are often used, with the material samples attached to an intra-oral splint. This allows examination of the biofilm grown on supragingival surfaces with Confocal Laser Scanning Microscopy (CLSM). However, the bacterial diversification of a biofilm from the peri-implantary region differs from that in other oral regions, because biofilms in the peri-implantary region can contain both 
aerobic and anaerobic bacteria [11]. It is therefore necessary to investigate the biofilm formation in the transmucosal area of implants, in order to allow comparison of different abutment materials under clinically relevant conditions.

The aim of the present study was therefore to determine the in situ adherence of oral biofilms to ceramic, gold and titanium in the perimplantary region.

\section{Materials and Methods}

This study was approved by the Ethics Committee of Hannover Medical School, Hannover, Germany (no. 3791), and each subject gave informed consent. This study included 8 male patients with single tooth implants in the posterior region. The patients were selected to fulfil the following inclusion criteria: no systemic illness, no current medication, no pregnancy, no active periodontitis and no pharmacological treatment or antibiotic therapy during or up to three months before the study. All patients had at least one oral two-piece titanium implant (Astra Tech, Mölndal, Sweden), which had been inserted three months before the investigation. Fourteen days after abutment surgery, the previously fitted healing abutments were removed and replaced by modified healing abutments (Zebra, Astra Tech, Mölndal, Sweden). On the day of abutment insertion, all patients received instructions on dental hygiene. Patients were instructed not to use any antimicrobial mouth rinses and to continue with their habitual oral hygiene procedures. Surgery was performed by the same clinician. No gingival trimming was performed. The modified healing abutments were removed after 14 days and subjected to further investigation.

\section{Abutment modification}

Slabs measuring $3.0 \times 1.5 \times 1.0 \mathrm{~mm}$ were produced from zirconia (ZrO2-TZP-A, Metoxit, Thayugen, Switzerland) and from a gold alloy (Mainbond Sun, Heraeus Kulzer GmbH, Hanau, Germany) and polished with a diamond suspension (MetaDi and MasterMet 2, Bueler, Duesseldorf) on a rotating disc in a polishing unit (PowerPro 4000 , Buehler, USA), giving a surface roughness of $\mathrm{Ra} \leq 0.2 \mu \mathrm{m}$ as measured with atomic force microscopy (AFM) (MFP-3D; Asylum Research, Santa Barbara, CA, USA) (Figure 1).

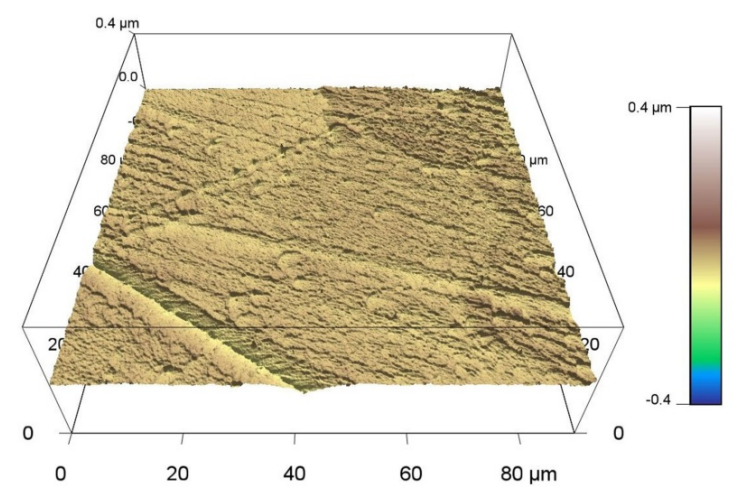

Figure 1: AFM picture of a polished sample with a surface roughness of $R_{a} \leq 0.2 \mu \mathrm{m}$.
On eight healing abutments, an area measuring $3.0 \times 2.0 \mathrm{~mm}$ was flattened in a standard milling machine and polished to the same surface roughness. This area acted as a titanium material specimen.

Two slots of the same size as the zirconia and the gold alloy specimens were drilled in the healing abutments and roughened by sandblasting with $110 \mu \mathrm{m}$ aluminium oxide particles. A zirconia and a gold alloy slap were glued into each abutment using Tetric-Flow adhesive (Ivoclar Vivadent, Schaan, Liechtenstein). The surface was polished with rotating polishing tips (Identoflex Dental Universal Polishers, Bioggio, Switzerland) to remove excess adhesive composite. Surface roughness was measured using AFM. The abutments were cleaned with ethanol and autoclaved at $134^{\circ} \mathrm{C}$ (Cassette Autoclave, SciCan, Canonsburg, PA 15317) (Figure 2).

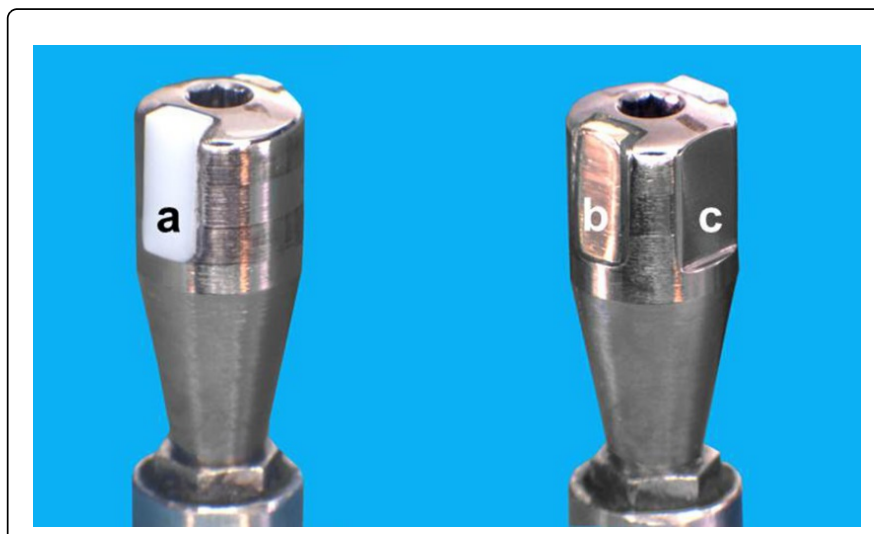

Figure 2: Modified healing abutments with a zirconia sample (a), a gold sample (b) and a polished titanium surface (c).

\section{Confocal laser scanning microscopy}

All abutments were stored after explantation in a saline buffer solution (B.Braun Melsungen AG, Germany) at $5^{\circ} \mathrm{C}$. Each abutment was stained by BacLight ${ }^{\oplus}$ LIVE/DEAD-Kit (Invitrogen, Karlsruhe, Germany). BacLight ${ }^{\oplus}$ is a one-step fluorescence-based assay for staining bacteria without fixation or membrane permeabilisation and contains the nucleotide acid stains SYTO 9 and propidium iodide. SYTO 9 generally stains all bacteria. In contrast, propidium iodide only penetrates perforated membranes, and thus suppresses SYTO 9 fluorescence when both dyes are present. In this way, bacteria with intact cell membranes are stained fluorescent green while bacteria with damaged membranes are stained fluorescent red.

After the staining procedures, the samples were placed in a saline buffer solution, followed by analysis with a confocal laser scanning microscope (Leica DM LFSA, Leica Microsystems GmbH, Wetzlar, Germany). Surface coverage of both materials with biofilm was assessed in the horizontal plane, starting from the top of the abutment at 10X magnification, and was subsequently quantified and represented in bright blue (areas covered by biofilm) or dark gray (areas not covered by biofilm) using surface analysis software (Adobe Photoshop CS2; Adobe Systems Inc., San Jose, CA USA).

To determine biofilm thickness, 10 vertical images were obtained from adjacent surface areas per specimen at 40X magnification and 2.4X zoom. These images were taken from a localisation on the abutment which was directly above the gingiva level. This measurement is based on five specific measurement points per image 
Citation: Ismail F, Eisenburger M, Grade S, Stiesch M (2016) In Situ Biofilm Formation on Titanium, Gold Alloy and Zirconia Abutment Materials.

Page 3 of 5

(LCS Lite 2.61; Leica Microsystems), for a total of 150 measurement points per specimen. Each measurement on the coated specimens was taken without considering individual surface roughness (lowest value measured). Finally, 3D-reconstructions of the biofilm formation were created (Imaris x64 6.2.1; Bitplane, Zurich, Switzerland) and mean biofilm thickness was measured for each specimen.

\section{Quantitative analysis of biofilm formation}

Statistical analysis was performed using IBM-SPSS version 21 for Windows (SPSS Inc., Chicago, IL, USA). As the Kolmorgorov-Smirnov Test showed that data were not normally distributed, a non-parametric test was used. Data were analysed for significant differences using the Kruskal-Wallis Test with a significance level of $\mathrm{p}<0.05$.

\section{Results}

The highest biofilm coverage was found on a titanium surface with $82 \%$, followed by two gold alloy surfaces with $62 \%$ coverage (Table 1 ). On ceramic, the highest biofilm coverage was $39 \%$. The highest biofilm thickness was measured with $64.8 \mu \mathrm{m}$ on a titanium surface, followed by $48.7 \mu \mathrm{m}$ and $33.9 \mu \mathrm{m}$ on two gold alloy surfaces. On ceramic, the highest biofilm thickness was $11.5 \mu \mathrm{m}$.

\begin{tabular}{|l|l|l|l|l|l|}
\hline \multicolumn{2}{|c}{} & Mean & SD & Min & Max \\
\hline \multirow{2}{*}{ Ti } & Thickness $[\mu \mathrm{m}]$ & 10.8 & 22.3 & 0.0 & 64.8 \\
\cline { 2 - 6 } & Coverage $\%$ & 26.5 & 30.8 & 0.0 & 82.0 \\
\hline \multirow{2}{*}{ ZrO2 } & Thickness $[\mu \mathrm{m}]$ & 2.7 & 4.1 & 0.0 & 11.5 \\
\cline { 2 - 7 } & Coverage \% & 10.5 & 14.4 & 0.0 & 39.0 \\
\hline \multirow{2}{*}{ Au } & Thickness $[\mu \mathrm{m}]$ & 14.6 & 17.6 & 0.0 & 48.7 \\
\cline { 2 - 7 } & Coverage $\%$ & 27.3 & 25.2 & 0.0 & 62.0 \\
\hline
\end{tabular}

Table 1: Biofilm thickness and percentage of biofilm coverage.

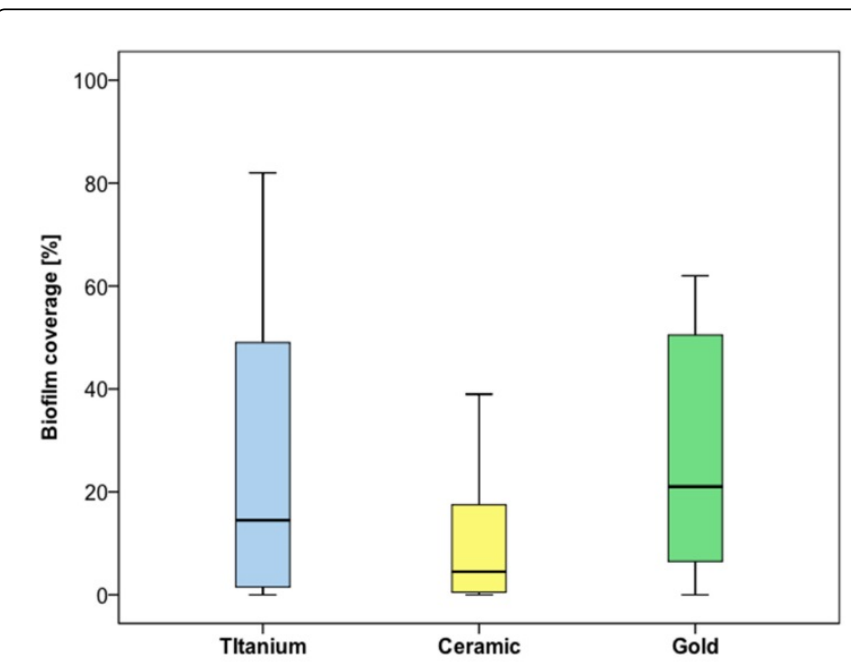

Figure 3: Box-plot diagram of average biofilm coverage. The differences were not statistically significant $(\mathrm{p}>0.05)$.
The abutments with the highest biofilm thickness were not the same abutments as the specimens with the highest biofilm coverage. One titanium surface, one gold alloy surface and two zirconia surfaces showed no biofilm formation.

The average biofilm coverage was $27.3 \% \pm 25.2 \%$ on gold surfaces, $10.5 \% \pm 14.4 \%$ on zirconia surfaces and $26.5 \% \pm 30.8 \%$ on titanium surfaces (Figure 3). The mean biofilm thickness was $14.6 \mu \mathrm{m} \pm 17.6 \mu \mathrm{m}$ on gold surfaces, $2.7 \mu \mathrm{m} \pm 4.1 \mu \mathrm{m}$ on ceramic surfaces and $10.8 \mu \mathrm{m} \pm$ $22.3 \mu \mathrm{m}$ on titanium surfaces (Figure 4 ). The differences in surface coverage and biofilm thickness were not statistically significant $(\mathrm{p}>0.05)$. A typical CLSM micrograph is shown in Figure 5.

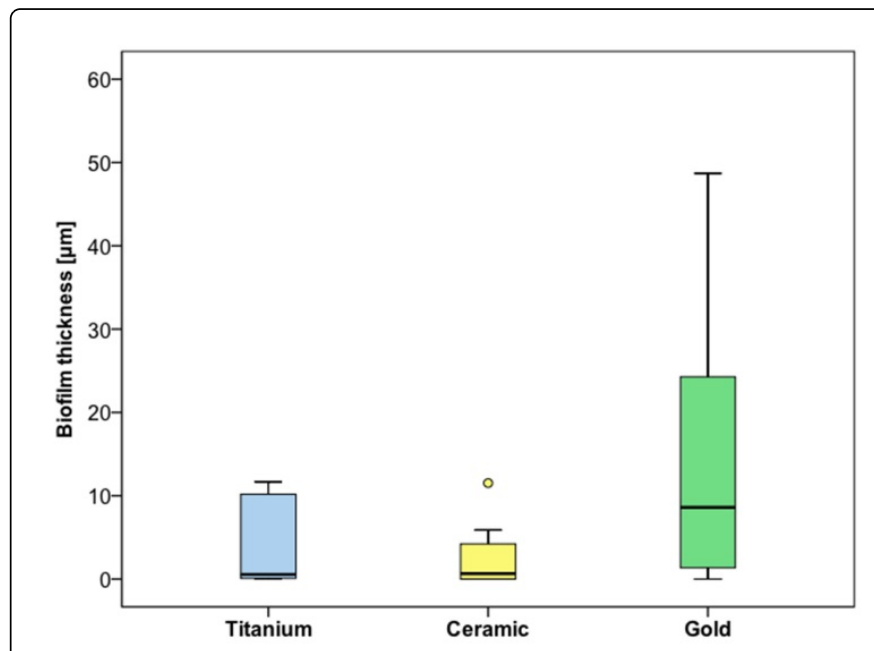

Figure 4: Box-plot diagram of average biofilm thickness. The differences were not statistically significant $(\mathrm{p}>0.05)$.
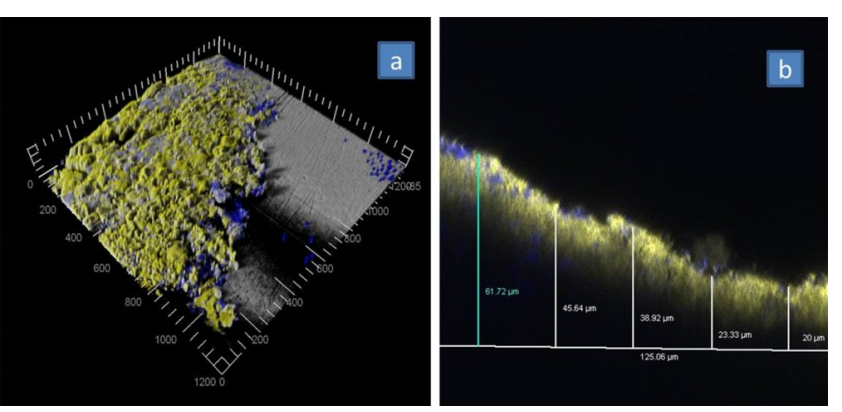

Figure 5: 3-dimensional reconstruction of biofilm formation using CLSM microscopy (a) and vertical height measurements (b).

\section{Discussion}

The current study investigates in-situ biofilm formation on different materials with dental implant healing abutments acting as supporting structure. All three materials are of clinical interest. The ZrO2-TZP-A zirconia from Metoxit (Thayugen, Switzerland) is produced for various commercially available CAD/CAM systems. The gold alloy Mainbond Sun (Heraeus Kulzer GmbH, Hanau, Germany) is a typical high grade gold alloy which can be fused to cast-to abutments. The type of 
titanium on which the biofilm formation was measured, is identical with the type of titanium which is used for abutments.

It is well known that surface roughness is an important factor for biofilm formation. An Ra value of $0.2 \mu \mathrm{m}$ has been shown to be critical for surface roughness, above which increased biofilm formation is seen $[12,13]$. Therefore the surface roughness of the samples was adjusted to $\mathrm{Ra} \leq 0.2 \mu \mathrm{m}$ to eliminate the influence of surface geometry. This eliminated the effects of surface roughness and allowed direct comparison of the three test materials, zirconia, gold alloy and titanium.

CLSM was used to assess biofilm formation, as this technique does not re-quire dehydration of the samples, biofilm embed $\neg$ ding or chemical fixation, as do other microscopy techniques. CLSM is an established technique to study the morphology of oral biofilms $[14,15]$ and allows the measurement of the height of the biofilm. As the abutments could be directly subjected to CLSM measurements, no biofilm was lost by harvesting the biofilm from intra-oral surfaces.

Various clinical studies have measured biofilm formation in similar in situ studies but material samples were positioned on intra-oral removable acrylic splints [16-18]. As a result, the conditions for biofilm formation were less clinically relevant than in the current study. The samples mounted on the acrylic splints usually had frictional contact to intraoral surfaces such as the buccal mucosa or tongue and this might have resulted in a constant self-cleaning effect. In contrast, in the current study the material samples had exactly the same position as an implant abutment or the cervical margin of an implant crown. This includes the direct vicinity to the peri-implant mucosa, with its local bacterial diversification and accessibility to habitual oral hygiene. Other studies exposed the samples to the oral environment for short periods, mainly for 24 hours [16,17,19,20]. A period of 14 days for biofilm growth was chosen in the current study, to ensure that the samples were exposed to normal oral hygiene and to normal oral activities during chewing. This mirrors the clinical condition of an abutment or crown surface.

Currently, other studies measure the race to the surface of human cells and bacteria on zirconia and titanium in vitro in a co-culture design [21,22]. De Avila compared colonisation on different material surfaces by different bacteria [23]. These studies have the advantage that the oral environment is mimicked better then in mono-culture studies with bacteria only, but are still in vitro studies. The current clinical study design has the advantage that the biofilm is directly grown in situ, insuring exactly the same biological environment to which implant abutments are exposed. Furthermore, the biofilm is simultaneously exposed to self-cleaning by contact to oral soft tissues and to oral hygiene procedures.

To reduce the risk of peri-implant infections, the material for implant abutments should possess specific properties which reduce biofilm adhesion. For tooth or implant supported crowns and bridges, dental materials such as gold alloys, titanium and ceramic are routinely used in prosthetic dentistry, although bacterial adhesion to these surfaces is observed clinically, especially in the cervical area. However, biofilm formation on different materials may not only be influenced by surface roughness and chemistry, but also by surface energy [24-26]. Higher surface free energy can facilitate bacterial adhesion to an intraoral hard surface [27]. In turn, lowering surface free energy resulted in less biofilm growth in in situ studies [27]. The surface free energy of a polished titanium surface is higher than that of a polished zirconia surface. Al-Radha et al. showed in vitro that this resulted in reduced bacterial growth on zirconia [28].

In the current study, no statistically significant difference in biofilm formation was found between gold alloy, titanium and zirconia. This can be explained by the fact that for each material some specimens had no or very little biofilm, both in terms of height and surface coverage. In contrast some patients had high biofilm formation on all three materials. It can be assumed that this is an effect of the individual patient. This resulted in a relatively high scattering of the data. A high standard deviation because of large interindividual differences has also been found in other clinical studies $[16,29,30]$. Also in an in-vitro coculture study of two bacteria species no differences in colonisation of titanium or zirconia was found [23]. However, the data of the current study show a tendency for lower biofilm formation on the zirconia surface. Further research with a larger sample size is warranted to check whether significantly lower biofilm formation on zirconia surfaces can be found.

Besides biofilm formation other clinical and technical parameters usually influence the decision to use an abutment material in an individual situation. Titanium abutments have the advantage of possessing greater mechanical stability than zirconia abutments. However, the aesthetics can be compromised if the grey shade of the abutments can be seen through a thin mucosa. Furthermore, in the long term, soft tissue retraction can expose the abutment, resulting in a dark cervical line. Zirconia abutments can avoid these negative effects, as they can be produced in various tooth coloured shades.

\section{Conclusion}

All three materials, gold alloy, titanium and zirconia, seem to be suitable materials for implant abutments with respect to biofilm formation. As height and surface coverage had the tendency to be lower for zirconia than for gold alloy and titanium, zirconia can be recommended as an abutment material with respect to its biological and aesthetic properties.

\section{Acknowledgement}

This study was approved by the Ethics Committee of Hannover Medical School, Hannover, Germany. The authors thank Astra tech (Mölndal, Sweden) for supplying implant material. The authors declare that they have no competing interests. The authors do not have any financial disclosure.

\section{References}

1. Harel N, Piek D, Livne S, Palti A, Ormianer Z (2013) A 10-year retrospective clinical evaluation of immediately loaded tapered maxillary implants. Int J Prosthodont 26: 244-249.

2. Romanos GE, Gaertner K, Nentwig GH (2013) Long-Term Evaluation of Immediately Loaded Implants in the Edentulous Mandible Using Fixed Bridges and Platform Shifting. Clin Implant Dent Relat Res 16: 601-608.

3. Mertens C, Meyer-Bäumer A, Kappel H, Hoffmann J, Steveling HG (2012) Use of 8-mm and 9-mm implants in atrophic alveolar ridges: 10year results. Int J Oral Maxillofac Implants 27: 1501-1508.

4. Quirynen M, De Soete M, van Steenberghe D (2002) Infectious risks for oral implants: a review of the literature. Clin Oral Implants Res 13: 1-19.

5. Clementini M, Rossetti PH, Penarrocha D, Micarelli C, Bonachela WC, et al. (2014) Systemic risk factors for peri-implant bone loss: a systematic review and meta-analysis. Int J Oral Maxillofac Surg 43: 323-334. 
Citation: Ismail F, Eisenburger M, Grade S, Stiesch M (2016) In Situ Biofilm Formation on Titanium, Gold Alloy and Zirconia Abutment Materials.

6. Geurs NC, Vassilopoulos PJ, Reddy MS (2010) Soft tissue considerations in implant site development. Oral Maxillofac Surg Clin North Am 22: 387-405.

7. Kohorst P, Herzog TJ, Borchers L, Stiesch-Scholz M (2007) Load-bearing capacity of all-ceramic posterior four-unit fixed partial dentures with different zirconia frameworks. Eur J Oral Sci 115: 161-166.

8. Auschill TM, Arweiler NB, Brecx M, Reich E, Sculean A, et al. (2002) The effect of dental restorative materials on dental biofilm. Eur J Oral Sci 110: 48-53.

9. do Nascimento C, Pita MS, Fernandes FH, Pedrazzi V, de Albuquerque Junior RF, et al. (2014) Bacterial adhesion on the titanium and zirconia abutment surfaces. Clin Oral Implants Res 25: 337-343.

10. Hahn R, Weiger R, Netuschil L, Brüch M (1993) Microbial accumulation and vitality on different restorative materials. Dent Mater 9: 312-316.

11. Klinge B, Hultin M, Berglundh T (2005) Peri-implantitis. Dent Clin North Am 49: 661-676, vii-viii.

12. Quirynen M, Bollen CM, Papaioannou W, Van Eldere J, van Steenberghe D (1996) The influence of titanium abutment surface roughness on plaque accumulation and gingivitis: short-term observations. Int J Oral Maxillofac Implants 11: 169-178.

13. Bollen CM, Papaioanno W, Van Eldere J, Schepers E, Quirynen M, et al. (1996) The influence of abutment surface roughness on plaque accumulation and peri-implant mucositis. Clin Oral Implants Res 7: 201-211.

14. Netuschil L, Reich E, Unteregger G, Sculean A, Brecx M (1998) A pilot study of confocal laser scanning microscopy for the assessment of undisturbed dental plaque vitality and topography. Arch Oral Biol 43: 277-285.

15. Wood SR, Kirkham J, Marsh PD, Shore RC, Nattress B, et al. (2000) Architecture of intact natural human plaque biofilms studied by confocal laser scanning microscopy. J Dent Res 79: 21-70.

16. Bremer F, Grade S, Kohorst P, Stiesch M (2011) In vivo biofilm formation on different dental ceramics. Quintessence Int 42: 565-574.

17. Yamane K, Ayukawa Y, Takeshita T, Furuhashi A, Yamashita Y, et al. (2013) Bacterial adhesion affinities of various implant abutment materials. Clin Oral Implants Res 24: 1310-1315.

18. Al-Ahmad A, Wiedmann-Al-Ahmad M, Faust J, Bächle M, Follo M, et al (2010) Biofilm formation and composition on different implant materials in vivo. J Biomed Mater Res B Appl Biomater 95: 101-109.
19. Scarano A, Piattelli M, Caputi S, Favero GA, Piattelli A (2004) Bacterial adhesion on commercially pure titanium and zirconium oxide disks: an in vivo human study. J Periodontol 75: 292-296.

20. Passariello C, Gigola P (2013) Adhesion and biofilm formation by periodontopathogenic bacteria on different commercial brackets. Eur J Paediatr Dent 14: 199-203.

21. Busscher HJ, van der Mei HC, Subbiahdoss G, Jutte PC, van den Dungen JJ, et al. (2012) Biomaterial-associated infection: locating the finish line in the race for the surface. Sci Transl Med 4: 153 rv10.

22. Zhao B, van der Mei HC, Subbiahdoss G, de Vries J, Rustema-Abbing M, et al. (2014) Soft tissue integration versus early biofilm formation on different dental implant materials. Dental materials: official publication of the Academy of Dental Materials 30: 716-727.

23. de Avila ED, Avila-Campos MJ, Vergani CE, Spolidorio DM, Mollo Fde A Jr (2016) Structural and quantitative analysis of a mature anaerobic biofilm on different implant abutment surfaces. J Prosthet Dent 115: 428-436.

24. Poortinga AT, Bos R, Busscher HJ (1999) Measurement of charge transfer during bacterial adhesion to an indium tin oxide surface in a parallel plate flow chamber. J Microbiol Methods 38: 183-189.

25. Teughels W, Van Assche N, Sliepen I, Quirynen M (2006) Effect of material characteristics and/or surface topography on biofilm development. Clin Oral Implants Res 17 Suppl 2: 68-81.

26. Hallab NJ, Bundy KJ, O'Connor K, Moses RL, Jacobs JJ (2001) Evaluation of metallic and polymeric biomaterial surface energy and surface roughness characteristics for directed cell adhesion. Tissue Eng 7: 55-71.

27. Quirynen M, Bollen CM (1995) The influence of surface roughness and surface-free energy on supra- and subgingival plaque formation in man, A review of the literature. J Clin Periodontol 22: 1-14.

28. Al-Radha AS, Dymock D, Younes C, O'Sullivan D (2012) Surface properties of titanium and zirconia dental implant materials and their effect on bacterial adhesion. J Dent 40: 146-153.

29. Elter C, Heuer W, Demling A, Hannig M, Heidenblut T, et al. (2011) Comparative analysis of biofilm formation on dental implant abutments with respect to supra- and subgingival areas: polytetrafluoroethylene versus titanium. Int J Prosthodont 24: 373-375.

30. Lindel ID, Elter C, Heuer W, Heidenblut T, Stiesch M, et al. (2011) Comparative analysis of long-term biofilm formation on metal and ceramic brackets. Angle Orthod 81: 907-914. 